\title{
DEVELOPMENT OF ACCOUNTING INFORMATION SYSTEMS AND THE BARRIERS FACED IN DEVELOPING NATIONS
}

\author{
Ali Serhan \\ Bucharest University of Economic Studies, Romania \\ Serhanali333@gmail.com
}

\begin{abstract}
Accounting Information Systems facilitate the automation of accounting information. The accounting information of an organization creates the foundation on which the entity's financial reports are generated. In spite of the fact that plenty of attention has been placed to the development and advancement of accounting professions in the developing countries, there has been very minimal emphasis placed in determining the implementation of accounting information systems. The main purpose of this research study is to examine the development of accounting information systems and the barriers that are experienced in developing nations, with a specific case study on Lebanon. The findings of the study established that the barriers include organizational structure, lack of technological advancements, poor training and education, and financial problems in the costly setting up of AIS. The strategies that organizations should take up include the training and education of managers and accountants within the organizations to gain competencies in carrying out accounting information systems, gain financially feasible contracts for setting up the systems and changing organizational structures to embrace advancements in technology.

Keywords: Accounting Information Technology, Organizational Culture, Middle Managers Commitment, Financial Problem, Environmental Factors.
\end{abstract}

\section{INTRODUCTION}

In the present day, dramatic and dynamic changes have taken place in the field of information technology (IT) and these advancements have substantially pervasive to the extent that they have generated changing trends in various areas. The fast-paced change in information technology, the extensiveness of user-friendly systems together with the massive inclination of organizations to obtain and implement informed and current computerized systems and software have resulted in computers being substantially simpler in being used. As a result, this has made it possible for accounting tasks to be achieved significantly faster and more precisely as compared to before. Some of the most significant features include exceedingly high precision, accessibility to information with high speed, processing data at a high 
speed, cost-effectiveness, and high-quality levels. Taking these factors into consideration, it is perceptible that there is no need at all for the justification of the utilization of IT in the present setting (Salehi, 2011). The accounting information system signifies a variety of sources encompassing both individuals and equipment, which are intended to gather financial data and information to attain the information necessitated for various decision makers. The utilization of accounting information is indispensable in managing activities of a firm owing to its quantitative data and information on different activities. Fundamentally, accounting information is purposed to be beneficial in financial and accounting decision making. Imperatively, accounting information is necessitated not just by management in the direction of the organization but also by shareholders who require periodic financial data so as to appraise the performance of the organization's management (Al-Dalabih, 2018).

Accounting is expected to provide data and information that is accurate and up to date. Accounting Information Systems facilitate the automation of accounting information. Imperatively, the accounting information of an organization creates the foundation on which the entity's financial reports are generated. Financial reporting is not restricted to the plain recording of financial transactions or a customary activity of bookkeeping but in fact renders information regarding the entity to a wide range of users to cultivate economic and financial decisions. Financial reports are documents that outline all of the financial activities of an entity and purposed to present its financial information in a clear and concise manner and easy to comprehend. Owing to the advancements of computers and technology, presently, financial reports are created electronically (Ezenwoke et al., 2019). The speed and direction of ICT innovation and associated organizational change, which encompass the object of study and examination of the field of information systems, are without a doubt instituted by the developed countries in the world, fundamentally in the European and North American regions. Nonetheless, in recent times, there has been an increase in innovation and espousal of IT in other regions of the world, especially in developing nations. However, it is perceptive that such expansion has not been fast and this is largely associated to the challenges faced in such developing nations (Avgerou, 2008).

\section{LITERATURE REVIEW}

Information Technology (IT) is a corporation's fundamental infrastructure that encompasses technology of resources that are irreplaceable, physical IT infrastructures, and IT of human resources to obtain information, for both managerial and technical competencies (Bharadwaj, 2000). A significant study problem within the accounting area and concern regarding accounting information system decision making within the organization takes into account communication and control of accounting information system (Salehi, 2011). Accounting information system is delineated as a significant mechanism of a company that 
is pivotal for efficacious management decision-making with respect to controlling an organization (Zimmerman, 1995). In overall, accounting information systems can be categorized into two different groupings including effective decision-making for information that is substantially for control of organization and secondly to facilitate information that is largely utilized for coordination of the company in regard to decision making.

Accounting information systems (AIS) is developed and advanced between one or more units of a corporation to attain a particular goal or objective. It comprises of small sub-systems that provide backing to bigger systems, and encompasses individuals, approaches, information, software as well as IT infrastructures (Ismail \& King, 2005). AIS consists of a group of incorporated elements that are associated to attain one or numerous specific goals in a manner that, if one or greater input can be placed into it, one or greater output can also exit. In delineation, accounting information system is an entirely designed system for the creation, collection, processing, storage, recovery, and distribution within an organization (Mitchell et al., 2000). It can be beneficial to an functional units within a business, more so for small and medium companies, in resolving short-term issues of managers in the aspect of costs incurred, prices set and also cash flow by rendering information to support and oversee medium and active corporations in a setting that is dynamic and competitive. AlS can also facilitate the integration of these businesses and the operational concerns and strategic programs in the longstanding period (Salehi \& Abdipour, 2013).

\subsection{Review of relevant empirical studies}

Salehi and Abdipour (2013) conducted a research study with the purpose of investigating the barriers of implementing accounting information systems, with a focus on the emerging economy of Iran. The authors formulated six hypotheses of accounting information systems comprising of organizational structure, financial issues, middle managers, organizational culture, human resources, and environmental factors. The study focused on the companies that are listed in the Tehran Stock Exchange. The results indicated that all of the formulated hypotheses were accepted. Based on the study, it can be inferred that granting rewards to managers and members of staff in addition to heartening the staff to utilize the new accounting systems will aid in the justification that the institution and implementation of the system would be beneficial to them (Salehi \& Abdipour, 2013).

In accordance to Shareia (2016), whereas a lot of consideration has been placed to the development of an accounting profession in developing nations, very minimal serious attention and action has been take to determining accounting objectives and development needs in such nations. Some of the major challenges faced is that accounting education and training within developing nations is week, with an observance to the source of accounting influence, regulations that are outdated and also the lack of competent instructors at companies and organizations. The accounting information systems that are being applied and utilized in 
companies are irrelevant and infrequent. This is owing to the lack of training in accounting and auditing. Furthermore, the author indicates that accounting in developing nations has not been given a great deal of value and worth and therefore, the accounting information that is formed by such accounting systems is hardly of any significant use. As a result, most developing countries do not see value in the role of accounting systems, nor their significance in each phase of their decision-making and nationwide development plans (Shareia, 2016).

Kuraesin et al. (2019) indicated that an accounting information system facilitates the collection, recording, storage and processing of data in order to generate information employed in decision making. The authors point out the significance of management commitment in the implementation of AIS in regard to the developing nation of Indonesia. Specifically, the authors indicated that there are a number of challenges that need to be carried out for effective implementation of AIS. First of all, there is need for idealized influence, which encompasses middle managers within the organization instituting trust and faith amongst the subordinates in regard to the direction taken by the organization. Secondly, there is the challenge of increasing confidence in the utilization of AIS to bring about an appealing vision, optimism and also significant expectations of using AIS. Lastly, there is also the challenge of poor training an education. This is because there is a significant need for providing training and advice in regard to the use of accounting information systems (Kuraesin et al., 2019).

\section{STATEMENT OF THE PROBLEM}

In the present-day setting, there has been increased level of spending and investment on information systems. In overall, information systems are developed using IT in order to help individual and organizations as a whole in carrying out their jobs. Progressively more developing nations are embracing advancements in technologies and accounting information systems. Accounting ought to be synchronized or united to make it more beneficial and suitable and broadly suitable to users of diverse markets or residents. As business and investment have come to be a global aspect, the internationalization and convergence of accounting has grown to be an inevitable outcome of combined determinations of worldwide and nationwide accounting regulatory and controlling administrations or bodies. It has been ascertained that for the most part, accounting systems have been espoused from developed nations devoid of any consideration being given to the local and environmental necessities, in spite of the irrelevance of these systems to these nations.

Research in accounting in nations that are either still in the process of developing, are still emerging or are still in transition that has gone ahead to be published in international journals has increased and built up in the past years largely and predominantly for the reason of the great economic interest that there is in these 
economies. The execution and implementation of the international accounting and financial standards has been regarded to be an appropriate and valid action, and also a kind of helping hand for foreign direct investment (FDI) and also trading. Nevertheless, the whole procedure of the adoption and in tum execution of the International Financial Reporting Standards (IFRS) cannot be perceived to be an easy one. Albu and Albu (2014) display and present the fact that the limitation of the publication of literature regarding research on the application of the IFRS concerning the developed nations is as a result of several causes encompassing the lack of available data. This includes lack of very important data and information that is based in IFRS that are not shared or recognized by the other institutions in the same manner or in no way at all. For these particular reasons, there is a restricted and inadequate comprehension and appreciation on the realizations and trials in numerous developing economies (Albu \& Albu, 2014).

In spite of the fact that plenty of attention has been placed to the development and advancement of accounting professions in the developing countries, there has been very minimal emphasis placed in determining the implementation of accounting information systems. Accounting information systems that are applied in corporations are not common or impertinent. The execution of accounting information systems in developing countries face a great deal of challenges as accounting in such regions is not largely valued and mostly such information generated from these systems is barely negligible (Shareia, 2016).

\subsection{Purpose of the study}

The main purpose of this research study is to examine the development of accounting information systems and the barriers that are experienced in developing nations, with a specific case study on Lebanon.

\subsection{Research Objectives}

The research study will be guided by the following objectives:

1. Identify the different barriers that are faced in the establishment of accounting information systems in organizations.

2. Identify different strategies for the institution of accounting information systems and eradicating obstacles in companies operating in Lebanon.

\subsection{Research Hypotheses}

The following are the formulated research hypotheses for the study: 
H1: Middle manager commitment within the organization hinder the institution of accounting information systems in various financial units.

H2: Organizational structure precludes the establishment of accounting information systems in the organization's various financial units.

H3: Organizational culture precludes the establishment of accounting information systems in the organization's various financial units.

H4: Financial problems and challenges preclude the establishment of accounting information systems in the organization's various financial units.

H5: Different environmental factors preclude the establishment of accounting information systems in the organization's various financial units.

\subsection{Significance of Study}

The significance of this research study is to enable the managers and organizations in developing nations as a whole to gain insight into the several challenges that hamper the implementation of accounting information systems. Importantly, this study will provide significant discernment into the different strategies and approaches that they can take in tackling these challenges and therefore effectively embrace, institute and implement accounting information systems within their organizations.

\section{METHODOLOGY}

Research design refers to the blueprint that is purposed at enabling the direction of a wide range of operations in research and therefore facilitates research in being well organized as possible so as to generate the greatest level of information (Kothari, 2004). It involves the decisions that are made regarding the techniques that are employed in the collection of data, the kind of strategies and research instruments for sampling that are employed and the manner in which the limitations in both cost and time can be handled. This research study employed the quantitative research approach. Specifically, the researcher employed the descriptive survey research design. It was deemed to be ideal for the study owing to the reason that it permits a methodical and properly organization description that is not only accurate but also valid and reliable (Denscombe, 2002). This research design has its endeavours directed toward the gathering of data from a populace, and that it delineates attaining phenomenon by making inquisitions from a sample of the target population concerning their perceptions and attitudes. 


\subsection{Population and Sample}

Target population can be defined as a uniquely definite group of people, elements, events as well as set of items under a research study (Kothari, 2004). The target population in this study encompassed financial and accounting managers in corporations. This is because these are the persons within the organizations that are directly responsible for the establishment and implementation of accounting information standards. The scope of the study encompassed corporations operating in Beirut. It is imperative to note that there are several companies operating in Beirut and the number of financial and accounting managers is highly substantial. Taking into consideration the constraints in time and resources, a suitable research sample was necessary. In definition, a research study sample comprises of entities that are obtained from the target population with an aim of approximating the population characteristics. Basically, sampling facilitates the selection of elements from a study population so that the same conclusions can be made regarding the total population (Cooper \& Schindler, 2003)

This research study employed the convenience sampling technique. This is a non-probability sampling method where the research participants are chosen owing to their convenient accessibility and proximity to the researcher. The research participants were chosen because they were easy to recruit for the research study and this technique was also advantageous owing to its fast and inexpensive approach. In total, 150 research participants were selected for the study.

\subsection{Research Instrument and Data Collection}

The research instrument is the tool the researcher uses to collect the required data (Bryman, 2008). In this study, questionnaires were considered to be the most ideal research instrument. A questionnaire is a technique for data collection that asks the subjects to provide either verbal or written responses to a particular set of questions. It is a fast, opportune and cost-effective method of gathering homogeneous data and information. Questionnaires can be utilized to gather information regarding knowledge, attitudes and experiences of subjects. Data was collected either in person, via email or via telephone.

\subsection{Validity and Reliability}

Reliability and validity are concepts that play a significant role in research as they assess the quality of research. They point out how properly a technique, method or particular test measures some aspects. On the one hand, reliability takes into account the consistency of a measure whereas validity takes into account the accuracy of a measure. This research study employed Cronbach's alpha in order to measure for internal consistency, which takes into account assessing how closely associated a set of items are as a group. This approach was deemed most ideal owing to the reason that the questionnaire comprised of multiple Likert questions and therefore the measure was used to determine whether the scale was reliable 
(Bolarinwa, 2015). In addition, the questions included in questionnaires were also sent to experts in the field to assess whether the questions were fitting.

\subsection{Data Analysis}

The gathered data was examined extensively and tested for completeness. The confirmed data was coded and thereafter keyed into Statistical Package for Social Sciences (SPSS). This statistical tool was utilized owing to the reason that it helped the researcher to organize and summarize the data to provide significant parameters, which are beneficial for data analysis. The analysis of data comprised the use of frequency distributions, percentages, correlation, means and standard deviation. Descriptive statistics was employed in presenting the research findings using bar graphs and tables. Subsequently, a summary of key findings and conclusions was provided so that the results of the study would be clearly understood.

\subsection{Ethical Considerations}

Abiding by the ethical guidelines is imperative when undertaking research, specifically in terms of official consent in addition to maintaining autonomy and anonymity of the research subjects (Bryman, 2008). Another important ethical consideration was participation. Imperatively, participation in the research study was completely voluntary and on the basis of informed consent. Basically, the research subjects were made aware of their choice and options of participating in the study and also the ability to withdraw their involvement at any given time they desired devoid of any repercussions. In addition, the research study was undertaken in line with the pertinent guiding principles on privacy and data protection. Research participants were not mandated to outline any personal information. Furthermore, personally recognizable particulars such as names of persons, organizations, and institutions were not incorporated in the final report. In conclusion, no financial inducements were provided to hearten participation in the research.

\section{FINDINGS}

The research sampled all of the 150 selected accountants and managers working in organizations in Beirut, Lebanon. A mean test was conducted to quantitatively delineate and summarize the collected information. Table 1 below presents the results of the mean test. Based on the findings, four key aspects were considered to be barriers of the development and implementation of accounting information systems in developing nations. Organizational structure is one of the barriers to the implementation of AIS in companies. Secondly, there is the aspect that lack of technological advancements hampers the development and implementation of AIS. Furthermore, the findings indicated that poor training and education is an additional barrier in regard to the use of accounting information systems and together with setting up AIS within organizations being a costly undertaking. 
Serhan A.

\subsection{Correlation Test Results}

This section also analyzed if the implementation of AIS is correlated with barriers. For a correlation to be approved, significance should score less than 0.05 . Correlation between implementing accounting information system and the lack of vision by middle managers in the organization to facilitate the development and implementation of AIS is approved since significance scored 0.000 which is less than 0.05. Secondly, correlation between implementing accounting information system and having a lack of trust and faith amongst subordinates in the development and implementation of AIS is approved since significance scored 0.000 which is less than 0.05 . Third, correlation between implementing accounting information system and having poor training and education in regard to the use of accounting information systems is approved since significance scored 0.000 which is less than 0.05 (Table 2).

TABLE 1: DESCRIPTIVE STATISTICS

\begin{tabular}{|c|c|c|c|}
\hline & $\mathrm{N}$ & Mean & Std. Deviation \\
\hline $\begin{array}{l}\text { Lack of vision by middle managers in the } \\
\text { organization to facilitate the development } \\
\text { and implementation of AIS }\end{array}$ & 150 & 3.2400 & .97403 \\
\hline $\begin{array}{l}\text { There is lack of trust and faith amongst } \\
\text { subordinates in the development and } \\
\text { implementation of AIS }\end{array}$ & 150 & 3.3667 & .74561 \\
\hline $\begin{array}{l}\text { Organizations do not see value in the role of } \\
\text { accounting systems, nor their significance in } \\
\text { each phase of their decision-making and } \\
\text { nationwide development plans }\end{array}$ & 169 & 3.3905 & .85295 \\
\hline $\begin{array}{l}\text { There is a progressing development of } \\
\text { accounting information systems (AIS) in the } \\
\text { organization }\end{array}$ & 150 & 3.4000 & .80268 \\
\hline $\begin{array}{l}\text { There are outdated regulations and also } \\
\text { there is the lack of proficient instructors }\end{array}$ & 150 & 3.4000 & .49154 \\
\hline $\begin{array}{l}\text { The organizational culture in companies } \\
\text { continue to prefer manual processes and } \\
\text { procedures }\end{array}$ & 150 & 3.4733 & 1.08496 \\
\hline $\begin{array}{l}\text { Organizational structure is one of the } \\
\text { barriers to the implementation of AIS in } \\
\text { companies }\end{array}$ & 150 & 3.5933 & .76058 \\
\hline $\begin{array}{l}\text { Lack of technological advancements hamper } \\
\text { the development and implementation of AIS }\end{array}$ & 150 & 3.6467 & .84454 \\
\hline $\begin{array}{l}\text { There is poor training and education in } \\
\text { regard to the use of accounting information } \\
\text { systems }\end{array}$ & 150 & 3.8400 & .36783 \\
\hline $\begin{array}{l}\text { Setting up AIS within organizations is a } \\
\text { costly undertaking }\end{array}$ & 150 & 4.0000 & .63457 \\
\hline Valid N (listwise) & 150 & & \\
\hline
\end{tabular}

Source: Generated in SPSS 
Fourth, correlation between implementing accounting information system and organizations do not see value in the role of accounting systems, nor their significance in each phase of their decision-making and nationwide development plans is approved since significance scored 0.000 which is less than 0.05 . Fifth, correlation between implementing accounting information system and having outdated regulations and also there is the lack of proficient instructors is approved since significance scored 0.000 which is less than 0.05. In addition, correlation between implementing accounting information system and setting up AIS within organizations is a costly undertaking is approved since significance scored 0.000 which is less than 0.05 (Table 2).

What is more, correlation between implementing accounting information system and having organizational culture in companies continue to prefer manual processes and procedures is approved since significance scored 0.000 which is less than 0.05 . The results also indicate that correlation between implementing accounting information system and the lack of technological advancements hamper the development and implementation of AIS is approved since significance scored 0.000 which is less than 0.05 . Lastly, correlation between implementing accounting information system and organizational structure is one of the barriers to the implementation of AIS in companies is approved since significance scored 0.000 which is less than 0.05 (Table 2).

\section{TABLE 2: CORRELATION TEST}

\begin{tabular}{|c|c|c|}
\hline & & $\begin{array}{l}\text { There is a } \\
\text { progressing } \\
\text { development of } \\
\text { accounting } \\
\text { information systems } \\
\text { (AIS) in the } \\
\text { organization }\end{array}$ \\
\hline \multirow{3}{*}{$\begin{array}{l}\text { Lack of vision by middle managers in the } \\
\text { organization to facilitate the development and } \\
\text { implementation of AIS }\end{array}$} & Pearson Correlation & $-.587^{\star \star}$ \\
\hline & Sig. (2-tailed) & 0.000 \\
\hline & $\mathrm{N}$ & 150 \\
\hline \multirow{3}{*}{$\begin{array}{l}\text { There is lack of trust and faith amongst } \\
\text { subordinates in the development and } \\
\text { implementation of AIS }\end{array}$} & Pearson Correlation & $-.381^{* *}$ \\
\hline & Sig. (2-tailed) & 0.000 \\
\hline & $\mathrm{N}$ & 150 \\
\hline \multirow{3}{*}{$\begin{array}{l}\text { There is poor training and education in regard to } \\
\text { the use of accounting information systems }\end{array}$} & Pearson Correlation & $-.327^{* *}$ \\
\hline & Sig. (2-tailed) & 0.000 \\
\hline & $\mathrm{N}$ & 150 \\
\hline \multirow{3}{*}{$\begin{array}{l}\text { Organizations do not see value in the role of } \\
\text { accounting systems, nor their significance in each } \\
\text { phase of their decision-making and nationwide } \\
\text { development plans }\end{array}$} & Pearson Correlation & $-.590^{* *}$ \\
\hline & Sig (2-tailed) & 0000 \\
\hline & & 150 \\
\hline \multirow{3}{*}{$\begin{array}{l}\text { There are outdated regulations and also there is } \\
\text { the lack of proficient instructors }\end{array}$} & Pearson Correlation & $-.408^{* *}$ \\
\hline & Sig. (2-tailed) & 0.000 \\
\hline & $\mathrm{N}$ & 150 \\
\hline
\end{tabular}


Serhan A.

DEVELOPMENT OF ACCOUNTING INFORMATION SYSTEMS AND THE BARRIERS FACED IN DEVELOPING NATIONS

\begin{tabular}{|c|c|c|}
\hline \multirow{3}{*}{$\begin{array}{l}\text { Setting up AIS within organizations is a costly } \\
\text { undertaking }\end{array}$} & Pearson Correlation & 0.000 \\
\hline & Sig. (2-tailed) & 1.000 \\
\hline & $\mathrm{N}$ & 150 \\
\hline \multirow{3}{*}{$\begin{array}{l}\text { The organizational culture in companies continue to } \\
\text { prefer manual processes and procedures }\end{array}$} & Pearson Correlation & $-.751^{* *}$ \\
\hline & Sig. (2-tailed) & 0.000 \\
\hline & $\mathrm{N}$ & 150 \\
\hline \multirow{3}{*}{$\begin{array}{l}\text { Lack of technological advancements hamper the } \\
\text { development and implementation of AIS }\end{array}$} & Pearson Correlation & $-.493^{\star \star}$ \\
\hline & Sig. (2-tailed) & 0.000 \\
\hline & $\mathrm{N}$ & 150 \\
\hline \multirow{3}{*}{$\begin{array}{l}\text { Organizational structure is one of the barriers to the } \\
\text { implementation of AIS in companies }\end{array}$} & Pearson Correlation & $-.446^{* *}$ \\
\hline & Sig. (2-tailed) & 0.000 \\
\hline & $\mathrm{N}$ & 150 \\
\hline
\end{tabular}

Source: Generated in SPSS

The following research hypotheses for the study were formulated:

H1: Middle manager commitment within the organization hinder the institution of accounting information systems in various financial units.

In order to test the first hypothesis, correlation test is employed, with the findings presented in Table 2. Correlation between implementing accounting information system and the lack of vision by middle managers in the organization to facilitate the development and implementation of AIS is approved since significance scored 0.000 which is less than 0.05 , showing the acceptance of the hypothesis. Therefore, $\mathrm{H} 1$ is approved.

H2: Organizational structure precludes the establishment of accounting information systems in the organization's various financial units.

Correlation between implementing accounting information system and organizational structure is one of the barriers to the implementation of AIS in companies is approved since significance scored 0.000 which is less than 0.05 as presented in Table 2. This shows the acceptance of the hypothesis. Therefore, $\mathrm{H} 2$ is approved.

H3: Organizational culture precludes the establishment of accounting information systems in the organization's various financial units.

Correlation between implementing accounting information system and having organizational culture in companies continue to prefer manual processes and procedures is approved since significance scored 0.000 which is less than 0.05 as presented in Table 2. This shows the acceptance of the hypothesis. Therefore, $\mathrm{H} 3$ is approved. 
H4: Financial problems and challenges preclude the establishment of accounting information systems in the organization's various financial units.

Correlation between implementing accounting information system and setting up AIS within organizations is a costly undertaking is approved since significance scored 0.000 which is less than 0.05 (Table 2). This shows the acceptance of the hypothesis. Therefore, $\mathrm{H} 4$ is approved.

H5: Different environmental factors preclude the establishment of accounting information systems in the organization's various financial units

Correlation between implementing accounting information system and the lack of technological advancements hamper the development and implementation of AIS is approved since significance scored 0.000 which is less than 0.05 . This shows the acceptance of the hypothesis. Therefore, $\mathrm{H} 5$ is approved.

\section{CONCLUSION}

The first objective of the study was to identify the various barriers that are faced in establishment and development of AIS in organizations. Based on the findings of the study, it was ascertained that the barriers include organizational structure, lack of technological advancements, poor training and education, and financial problems in the costly setting up of AIS. These findings are in line with existent studies that indicated poor training and education amongst personnel in organizations hampering the undertaking (Kuraesin et al., 2019). There is also the aspect of the lack of competent instructors at companies and organizations (Shareia, 2016). In addition, based on their structures, organizations in developing nations do not consider AlS to be pertinent to the success of operations (Shareia, 2016).

The second objective of the study was to identify different strategies for the institution of accounting information systems and eradicating obstacles in companies operating in Lebanon. First and foremost, one of the key strategies is to facilitate the training and education of managers and accountants within the organizations to gain competencies in carrying out accounting information systems. Secondly, there is the strategy that organizations should embrace the advancements in technology to enable smooth and efficient development and execution of accounting information systems. This is in line with the change in organizational structure, with middle managers being given the forefront of placing trust and understanding amongst subordinates to take up the change in the organization. Third, organizations can seek out contracts with the developers of accounting information systems to establish a way of payment in order to ease the costly set up.

This study had a limitation of information accessibility in addition to the inclination to fill in and complete the questionnaires. This is largely because the respondents included financial managers and accountants of the organization who were not easy to gain accessibility to and the researcher had to contact them 
severally. In addition, this study was solely limited to organizations operating in Beirut since the time and resources could not permit the researcher to conduct an expensive and comprehensive study on numerous organizations. Furthermore, the study sought to establish the barriers faced in developing nations in the development and implementation of AIS. This study focused on Lebanon. However, it is imperative to note that the environmental factors are situations might be dissimilar in other developing nations and therefore other factors might create barriers.

\section{REFERENCES}

Albu, N., Albu, C. N. (2014). Editorial IFRS application in Central and South-Eastern European countries. Accounting and Management Information Systems Vol. 13, No. 2, pp. 182-197.

Al-Dalabih, F. A. (2018). The Impact of the Use of Accounting Information Systems on the Quality of Financial Data. International Business Research, 11(5), 143-158.

Avgerou, C. (2008). Information systems in developing countries: a critical research review. Journal of information Technology, 23(3), 133-146.

Bharadwaj A. S. (2000). A resource-based perspective on information technology capability and firm performance: an empirical investigation, MIS Quarterly; 24(1):169-196.

Bolarinwa, O. A. (2015). Principles and methods of validity and reliability testing of questionnaires used in social and health science researches. Nigerian Postgraduate Medical Journal, 22(4), $195-201$.

Bryman, A. (2008). Social research methods. 3rd ed. Buckingham: Open University Press.

Cooper, D. R., \& Schindler, P. S. (2003). Business Research Methods. New Delhi: Tata McGraw Hill.

Denscombe, M. (2002). Ground rules for good research. New York: Open University Press.

Ezenwoke, O., Ezenwoke, A., Eluyela, D., \& Olusanmi, O. (2019). A Bibliometric Study of Accounting Information Systems Research from 1975-2017. Asian Journal of Scientific Research, 12, 167-178.

Ismail, N. A., \& King, M. (2005). Firm performance and AIS alignment in Malaysian SMEs. International Journal of Accounting Information Systems, 6(4), 241-259.

Kothari, C. R. (2004). Research methodology: Methods and techniques. New Age International.

Kuraesin, A. D., Yadiati, W., Sueb, M., \& Fitrijanti, T. (2019). The Effect of Management Support on the Quality of Accounting Information Systems and Its Impact on the Quality of Accounting Information (In Private Higher Education in Bandung City). International Journal of Mechanical Engineering and Technology, 10(3), 450-456.

Mitchell, F., Reid, G. C., \& Smith, J. (2000). Information system development in the small firm: The use of management accounting. Chartered Institute of Management Accountants.

Salehi, M. (2011). A study of the barriers of implementation of accounting information system: Case of listed companies in Tehran Stock Exchange. Journal of Economics and Behavioral Studies, 2(2), 7685.

Salehi, M., \& Abdipour, A. (2013). Accounting information systems barriers: Case of an emerging economy. African Journal of Business Management, 7(5), 298-305.

Shareia, B. (2016). Accounting Information Systems in Developing Countries. Journal of Business and Economic Policy, 3(1), 46-57.

Zimmerman J. L. (1995). Accounting for decision-making and control. Chicago: Irwin. 